\title{
Precedente en materia de hechos
}

\author{
Álvaro Núñez Vaquero*
}

\begin{abstract}
RESUMEN
El presente trabajo parte respondiendo afirmativamente a la pregunta acerca de si son posibles precedentes en materia de hechos para, a continuación, intentar establecer qué tipos de precedentes puede haber en materia de hechos. Para ello, en primer lugar se aclaran las nociones fundamentales en relación con los precedentes: stare decisis, ratio decidendi ( $y$ obiter dicta) y precedente. En segundo lugar se explica por qué constituye una mala idea afrontar el tema de los precedentes por medio de una doctrina normativa de las fuentes del derecho. En tercer lugar se disuelve una ambigüedad que afecta a la expresión "bechos probados", y se aclara en qué sentido puede haber precedente en materia de hechos. En cuarto lugar se distingue entre precedentes en materia de hechos en sentido estricto, y precedentes probatorios, introduciendo algunas otras distinciones para diferenciar entre varios tipos de precedentes. En quinto lugar se hace una breve llamada de atención acerca de los límites del precedente como estrategia para aumentar la seguridad jurídica. Se finaliza con unas breves conclusiones.
\end{abstract}

Precedente sobre hechos - enunciado calificatorio - norma constitutiva

\section{Precedents about facts}

\begin{abstract}
The present paper begins answering affirmatively to the question about if it is possible to bave precedents in the subject of facts, and then tries to establish what types of precedents may exist in the matter of facts. To do this, firstly, the fundamental notions in relation to precedents are clarified: stare decisis, ratio decidendi (and obiter dicta) and precedent. Secondly, it explains why it is a bad idea to address the issue of precedents through a normative doctrine of the sources of
\end{abstract}

* Licenciado en Ciencias Jurídicas, Universidad Autónoma de Madrid, España. Doctor en Filosofía del Derecho y Bioética Jurídica, Universitá degli Studi di Genova, Italia. Profesor de Teoría del Derecho, Universidad Austral de Chile. Para la elaboración de este trabajo han sido fundamentales las conversaciones con Iván Hunter, Juan Sebastián Vera, Diego dei Vecchi y Daniela Accatino, a quienes solo les puedo estar agradecido por ayudarme a resolver unas cuantas dudas. Además, Diego dei Vecchi y Daniela Accatino hicieron acertadas observaciones a una versión previa de este trabajo, señalando varios problemas. Damiano Canale y Daniel González Lagier hicieron valiosas observaciones al texto. Una versión previa de este trabajo fue discutida en el Seminario Austral de Derecho, de la Universidad Austral de Chile, en un Seminario en la Universitat de Girona, otro en la Universidad de Mar del Plata, y en las I Jornadas de Derecho Probatorio de Chile.

Artículo recibido el 16.5.2017 y aceptado para su publicación en este número el 5.1.2018. 
law. Thirdly, an ambiguity that affects the expression "proven facts" is dissolved, and it clarifies in what sense may exist precedent in fact. Fourthly, it distinguishes between precedents in the subject of facts in the strict sense, and precedents of evidence, introducing some other distinctions to differentiate between several types of precedent. Fifthly, a brief attention is drawn to the limits of precedent as a strategy to increase legal certainty. It concludes with a few considerations.

Factual precedent - calificative statement - constitutive norm

\section{INTRODUCCIÓN}

$\mathrm{P}$ ese al creciente interés registrado en los últimos años en el mundo del civil law, el tema de los precedentes jurisdiccionales sigue siendo aún un terreno no suficientemente explorado. Y si bien el tema ha sido ampliamente tratado en la tradición del common law, quedan aún múltiples aspectos sin explorar del mismo.

Dentro de esta falta de desarrollo, llama especialmente la atención la casi total ausencia de tratamiento de un tipo particular de precedentes: los precedentes en materia de hechos ${ }^{1}$. Con certeza, tal falta de atención acerca de este tipo de precedentes no se ha debido exclusivamente a la ausencia de interés o poca imaginación, sino al menos también a otras tres razones.

La primera de ellas es que los precedentes, al menos según buena parte de la literatura, son normas, formuladas o aplicadas por tribunales, que deberían ser empleadas por otros tribunales (o por el mismo tribunal) para casos futuros similares; es decir, para aplicar un precedente es necesario que los hechos del caso sean similares. De este modo, requerir la similitud de los hechos para aplicar un precedente en materia de hechos da a todo el argumento una cierta apariencia de circularidad.

La segunda razón es que tradicionalmente se ha considerado, sobre todo en el ámbito del civil law, que quienes son -o han de ser considerados- competentes para dictar precedentes son los órganos judiciales situados en la cúspide de los sistemas judiciales. El problema es que dichos tribunales normalmente tienen vedado el conocimiento de los hechos del caso. Además, según afirman algunos autores, debido a la falta de inmediatez con los hechos del caso, es bueno que los tribunales superiores no entren a establecer precedentes en materia de hechos ${ }^{2}$.

La tercera y última razón es que los enunciados respecto de hechos son, o al menos parecen ser, enunciados descriptivos. Por su parte, los precedentes suelen ser considerados como normas, por lo que, desde este punto de vista, todo aquello que tiene que ver con los hechos parece mal candidato para convertirse en precedente.

${ }^{1}$ Una primera aproximación al tema se encuentra en Trento, S. "El problema de la formación de precedentes en materia probatoria por tribunales supremos. El imperativo que las decisiones judiciales relativas a la prueba de los hechos sean universalizables", en Ferrer, J. y Vázquez, C. (eds.), Debatiendo con Taruffo, Marcial Pons, Madrid, 2016. En un sentido diferente, Romero Seguel, A. "La sentencia judicial como medio de prueba”, en Revista Chilena de Derecho, 39, 2, 2012.

${ }^{2}$ Si bien escribe en el ámbito del common law, Allison Orr Larsen sostiene precisamente esta tesis. Véase Allison Orr Larsen, "Factual Precedents", en University of Pennsylvania Law Review, 162, 59, 2013. 
El presente trabajo viene a intentar colmar, aunque sea solo parcialmente, esta laguna en la literatura. La pregunta de la que parte es la siguiente: ¿es posible que haya precedentes en materia de hechos? No obstante, la pregunta es respondida inmediatamente -sí, es perfectamente posible-y sustituida por la pregunta acerca de qué tipos de precedentes podemos encontrar y qué forma tienen. El objetivo del trabajo es reconstruir los tipos de precedentes en relación con los hechos que podemos encontrar, y de hecho encontramos, en nuestros ordenamientos. Así se distinguirá entre precedentes respecto de hechos en sentido estricto y precedentes relativos al derecho probatorio ${ }^{3}$. No será objeto de este trabajo, sin embargo, la plausibilidad o la bondad de tener precedentes en materia de hechos ${ }^{4}$.

Antes de entrar a analizar qué tipos de precedentes en materia de hechos podemos tener, es necesario afrontar el problema previo de definir qué son los precedentes y de cuándo está justificado decir que tenemos un sistema de precedentes en un determinado ordenamiento. Debido a que aquí se concibe el análisis conceptual de manera débil, no se intentará buscar el "verdadero" concepto de precedente que supuestamente mejor representaría nuestras prácticas y creencias acerca de qué es el derecho y qué son los precedentes (análisis conceptual fuerte, tal y como lo concibe Raz ${ }^{5}$ ), sino que me conformaré con buscar un concepto de precedente útil a los fines de la explicación que aquí se intentará ofrecer (análisis conceptual débil) ${ }^{6}$. Para que el concepto sea útil a mis fines ha de ser un concepto comprensivo, ya que parece que los precedentes en materia de hechos no parecen ser el caso paradigmático de precedente (al tiempo que no traicione los usos lingüísticos de nuestras comunidades jurídicas $)^{7}$. Sin embargo, como se verá enseguida, resulta plausible hablar de precedentes en materia de hechos.

\section{I. ¿QUÉ SON LOS PRECEDENTES?}

Para no incurrir en limitaciones conceptuales que impidan abordar el fenómeno de los precedentes en materia de hechos, es preciso partir con un breve análisis de la propia noción de precedente. Ello porque asumir un concepto demasiado restrictivo de precedente supondría no poder dar cuenta del papel que juegan afirmaciones y decisiones

${ }^{3}$ Son precedentes respecto de hechos en dos sentidos diferentes, pero en ambos casos son precedentes que afectan a la fijación de hechos en procedimientos jurisdiccionales posteriores.

${ }^{4}$ Larsen, A. O., "Factual Precedents", ob. cit.

${ }^{5}$ Véase Raz, J. “¿Puede haber una teoría del derecho?”, en Raz, J., Alexy, R. y Bulygin, E., Una discusión sobre teoría del derecho, Marcial Pons, Madrid, 2007.

${ }^{6}$ Véase el trabajo introductorio de Bouvier, H., Gaido, P. y Sánchez Brígido R., en Raz, J., Alexy, R. y Bulygin, E., Una discusión sobre teoría del derecho, ob. cit.

${ }^{7}$ No es, sin embargo, la única razón. El presente trabajo se enmarca dentro de los primeros pasos de una investigación que pretende (re)construir una teoría del precedente común tanto a los ordenamientos del common law como del civil law y, como se verá enseguida, no únicamente judiciales, sino jurisdiccionales en sentido amplio. De este modo, se opta por un concepto de precedente capaz de dar cuenta del mayor número de situaciones posibles, sin traicionar, no obstante, los usos más comunes del lenguaje de los juristas. 
relativas a hechos -realizadas por órganos jurisdiccionales- en la justificación de decisiones posteriores. Pero para ello es preciso distinguir la noción de precedente de otras dos nociones, cercanas pero diferentes: stare decisis y ratio decidendi.

\section{Stare decisis}

Por stare decisis podemos entender aquella norma que "obliga" a los órganos a decidir los casos similares del mismo modo. Es preciso entrecomillar el término "obliga" porque aquí no estamos frente a una norma prescriptiva que obligue a los jueces, so pena de alguna sanción, a decidir del mismo modo que se han resuelto otros casos pasados similares $^{8}$. Por el contrario, estamos frente a una norma constitutiva que considera que una norma -aquella expresada o empleada por el tribunal (lo que a continuación llamaremos ratio decidendi) - constituye al menos una razón en la argumentación de decisiones jurisdiccionales posteriores.

Es importante señalar que no existe una única norma del stare decisis, sino una importante variedad de normas que califican normativamente el decidir del mismo modo que se ha decidido en el pasado. Es en este sentido en el que es posible entender que aquella es una "obligación" gradual: no porque se trata de una "obligación" -que tampoco- que admite, al modo de los mandatos de optimización, diferentes grados de cumplimiento, sino porque hay diferentes normas del stare decisis que dotan de mayor o menor relevancia normativa a los precedentes ${ }^{9}$. En particular, la regla del stare decisis establece condiciones necesarias, suficientes o contribuyentes para la validez de la decisión jurisdiccional; más en concreto, de la aplicabilidad de la norma individual producto de la decisión ${ }^{10}$.

${ }^{8}$ Es posible que, además de la norma del stare decisis, que es una norma constitutiva, haya también alguna norma prescriptiva que venga a sancionar el no seguimiento del stare decisis (como, por ejemplo, en el caso de las decisiones jurisdiccionales que no siguen los dictámenes de la Contraloría chilena). No obstante, no puede existir sistema de precedentes sin norma constitutiva, pero sí en ausencia de normas prescriptivas. Ello debido a que si solo hubiese norma prescriptiva, el no seguimiento de ella acarrearía sanciones para el juez que se desvía, pero su decisión seguiría siendo válida (piense, por ejemplo, en los casos de prevaricación donde hay sanción para el sujeto pero no se anulan automáticamente sus decisiones). La invalidez es normalmente considerada la principal consecuencia del no seguimiento del precedente.

${ }^{9}$ Precisamente esta variedad de grados de relevancia es la que me lleva a no definir el stare decisis (y los precedentes) como normas absolutamente vinculantes, como hace buena parte de la literatura, proveniente especialmente del common law. Si pretendemos dar cuenta de cómo funcionan los precedentes en ordenamientos de ambas tradiciones, es preciso emplear un concepto más amplio que permita dar cuenta de la mencioada heterogenidad.

${ }^{10}$ Por consiguiente, no siendo las normas individuales producto de la sentencia válida -al menos en la posición de Bulygin, que aquí no discutiré- el stare decisis sería condición de aplicabilidad y eficacia de la norma individual producto de la decisión jurisdiccional posterior que aplica el precedente. Qué tipo de condición -necesaria, suficiente, contribuyente- dependerá de lo dispuesto por cada ordenamiento. No obstante, es preciso señalar -debido a que un evaluador incide en este punto- que las condiciones de aplicabilidad, validez o eficacia de normas pueden ser otras normas como, por ejemplo, el caso en el que la norma que define qué es un funcionario es condición de aplicabilidad de las normas acerca de la remuneración de los funcionarios. 
A título meramente ejemplificativo, es posible señalar los dos extremos -máximo y mínimo- de los grados de relevancia normativa de los precedentes y algunos grados intermedios, reflejos de diferentes reglas del stare decisis. En el grado máximo encontramos la norma en la que cualquier decisión que no siga la decisión -considerada como- precedente es directamente inválida y, por tanto, nula ${ }^{11}$. En el grado mínimo es posible encontrar la norma en donde el precedente es un argumento esgrimible frente a un tribunal (i.e. forma parte de la clase de las razones jurídicas). Y en medio, por supuesto, encontramos una enorme variedad de normas intermedias: desde aquella donde el precedente constituye una razón suficiente para la justificación de la decisión judicial, hasta aquella en la que los precedentes constituyen razones meramente contribuyentes ${ }^{12}$.

Con seguridad no se trata únicamente de una sola regla acerca de la relevancia normativa de los precedentes, sino que hay una gran multiplicidad de normas en relación con el precedente como, por ejemplo, la regla de reconocimiento de los precedentes, aquella acerca de su derogación y modificación, los criterios para resolver sus antinomias, los mecanismos para la determinación autoritativa de la ratio, etc. Más bien, las normas relativas al precedente -incluida aquella que establece la vinculatoriedad de determinadas normas, pero también otras relativas a los aspecto apenas mencionados- configuran intrincados microsistemas normativos, en muchas de las ocasiones conformados por normas implícitas.

\section{Ratio decidendi ( $y$ obiter dicta)}

Uno de los aspectos en los que más se ha llamado la atención en temas de precedentes es la noción de ratio decidendi. Este no es el lugar indicado para abordar con el detenimiento necesario las diferentes nociones de ratio decidendi, pero sí para indicar cuáles han sido las principales concepciones respecto de aquella. Pues bien, en la literatura parece haber un cierto consenso acerca de que la ratio decidendi es la norma empleada

${ }^{11}$ Es dudoso que tal regla del stare decisis haya existido, y seguro que actualmente no existe, al menos en los ordenamientos de nuestro entorno. No obstante, no hay ninguna razón conceptual por la que tal norma no pudiese existir. El único momento en el que una tal regla parece que estuvo vigente fue a mediados del siglo XX en Inglaterra. Se considera que desde la derogación de la norma que impedía a la Cámara de los Lores entrar a revisar sus propios precedentes, el único ejemplo de dicho sistema desapareció. Véase Cross, R. y Harris, J., El precedente en el Derecho inglés, Marcial Pons, Madrid, 2012, pp. 129 ss.

12 Señala Mercedes Fernández que el Tribunal Supremo español ha señalado que sus precedentes en materia de hechos no son "obligatorios", sino pautas útiles o reglas de experiencia (Cfr. Fernández López, M. "La valoración de pruebas personales y el estándar de la duda razonable", en Cuadernos electrónicos de Filosofía del Derecho, 15, 2007, n. 7). Esto parecería apoyar las hipótesis de que, o bien no son en absoluto precedentes, o bien que existen precedentes sin ningún grado de vinculatoriedad. Pero resulta útil preguntarse si una decisión justificada con base en las opiniones del Tribunal Supremo se considera que está mejor fundamentada que otra que llega a conclusiones igualmente justificadas prima facie, pero incompatibles con lo dicho por el Tribunal. Si la respuesta es afirmativa, aunque tengan un grado bajo de vinculatoriedad, parece que se trata pese a ello de precedentes normativamente relevantes. 
como premisa mayor de la decisión judicial ${ }^{13}$, y desacuerdo sobre si hay que añadir algo más ${ }^{14}$. En efecto, para algunos es necesario añadir los hechos del caso; para otros, todas las consideraciones necesarias para la decisión del caso que constituye precedente; y para algunos otros todavía, es la norma que constituye la premisa normativa del silogismo práctico que justifica la decisión judicial más el conjunto de todos los argumentos de la justificación de la decisión.

Aquí voy a rechazar estas tres tesis acerca de qué es la ratio decidendi por ser las tres reductivas. La razón es que en algunas ocasiones se ha considerado como ratio decidendi no la norma que justifica la premisa normativa -más, eventualmente, algún otro conjunto de consideraciones-, sino únicamente una norma empleada (o a veces solo formulada) en la justificación externa de la decisión jurisdiccional. De este modo, es posible que sea considerada ratio decidendi una norma que forma parte de la justificación interna o externa de la decisión, pero no la totalidad del razonamiento judicial, ni solo la premisa que funciona como premisa mayor del silogismo práctico cuyo resultado es la decisión jurisdiccional. Así, podrán ser rationes decidendi de un caso normas, por ejemplo, de carácter procesal que establecen la competencia del órgano para juzgar (que son condición necesaria pero no suficiente para una decisión respecto del fondo), normas de carácter interpretativo que fijan el sentido a atribuir a textos normativos (sobre todo constitucionales, pero también legales) normas que establecen jerarquías entre otras normas (por ejemplo, concernientes a las relaciones entre tratados internacionales y legislación interna), o normas empleadas como premisa mayor del silogismo que justificaría la decisión jurisdiccional.

La aproximación tradicional tiene problemas para dar cuenta de la posibilidad de que una norma de la justificación externa de la decisión pueda, por sí misma, constituir la ratio decidendi del caso. La razón pasa por cómo viene trazada otra importante distinción: aquella entre ratio decidendi y obiter dicta. En efecto, la ratio decidendi es configurada, al mismo tiempo, de dos maneras diferentes: por un lado, como un criterio estructural de la decisión (una parte de la sentencia judicial); y, por el otro, como la parte vinculante de la decisión. Especularmente, el obiter dicta es definido como todo aquello que no forma parte de la ratio decidendi y, por ello, no es obligatorio.

Más allá de que, en la forma tradicional en la que es trazada, la distinción tiene fronteras móviles - porque cuál sea considerada la ratio y cuál el obiter de una decisión puede cambiar, y de hecho cambia, en ocasiones con el tiempo-, el problema es que, de hecho, se atribuye valor vinculante a normas diferentes a la que constituye la premisa

${ }^{13}$ No obstante, este consenso no es total, y probablemente sea superficial. Para los diferentes conceptos de ratio decidendi disponibles, véase Chiassoni, P., "Los precedentes civiles son vinculantes", en Desencantos para abogados realistas, Bogotá, Universidad del Externado, 2012.

${ }^{14}$ Punto de referencia en esta materia es el debate entre Goodhart, Montrose y Simpson. Para un resumen del debate, véase Cross, R., El precedente en el Derecho inglés, ob. cit., cap. II. 
normativa del silogismo judicial ${ }^{15}$, siendo consideradas ratio decidendi normas que forman parte de la justificación externa ${ }^{16}$. En ocasiones, tal premisa normativa del caso considerado precedente queda incluso totalmente carente de valor vinculante para decisiones futuras ${ }^{17}$.

Basado en las consideraciones anteriores, definiré ratio decidendi precisamente como aquella norma empleada, o meramente formulada, en la justificación interna o externa de una decisión jurisdiccional, que es calificada como normativamente relevante por la regla del stare decisis para casos diferentes a aquel en el que fue formulada. Esta definición de ratio decidendi -no se opone sino que- engloba a las tres posiciones clásicas antes mencionadas. En efecto, desde el punto de vista aquí adoptado nada impide que se considere en la práctica de un ordenamiento jurídico como ratio decidendi no únicamente una norma de la justificación de la decisión, sino la suma de aquella más -por ejemplo- todas las consideraciones necesarias para alcanzar la decisión; o bien que de hecho sean consideradas rationes decidendi solo normas empleadas en la justificación interna de las decisiones jurisdiccionales. Mi definición es mínima y pretende englobar al resto de definiciones, comprendiendo al mismo tiempo las posibles variantes de la práctica de identificación de la ratio (entendida como una norma a la que se le atribuye valor normativo para resolver otros casos).

\section{Precedentes}

A estas alturas podría inferirse qué estoy entendiendo por "precedente". Sin embargo, resulta conveniente delinear de manera expresa y precisa cómo estoy empleando la expresión. Por "precedente" entiendo cualquier decisión de carácter jurisdiccional que expresa al menos una norma a la que se le dota de algún valor normativo para casos diferentes a aquel en cuyo contexto fue dictada ${ }^{18}$. Se trata, por tanto, de una propiedad de las decisiones jurisdiccionales que puede estar presente o ausente en las mismas, que se constatará en un caso concreto en la medida en que una norma le otorgue tal propiedad a una decisión o conjunto de decisiones jurisdiccionales. Dicho de otro modo, estaremos

${ }^{15}$ De hecho, este es el caso menos frecuente, siendo mucho más habitual que aquello a lo que se le atribuye valor normativo sea una norma diferente a la empleada en la justificación interna de la decisión.

16 Aquí no estoy defendiendo la idea, de índole normativa, según esta, es bueno o positivo que se empleen normas diferentes a aquella que constituye la premisa mayor del silogismo judicial, ni tampoco que sea bueno que sean normas meramente formuladas y no empleadas. Lo único que digo es que es posible, y de hecho sucede, considerar esas normas como la ratio decidendi de alguna sentencia.

${ }^{17}$ Por poner solo un ejemplo: la sentencia judicial que resolvió el caso del aceite de colza en España aplicó la norma en la que la prueba por indicios puede ser considerada suficiente, al menos en determinados contextos. Es decir, la norma que fue empleada para futuras decisiones jurisdiccionales no era una norma que formase parte de la justificación interna de la decisión, sino de la justificación externa.

${ }^{18}$ Resulta importante señalar que las decisiones jurisdiccionales y, por tanto, también los precedentes son conjuntos de enunciados lingüísticos. Nótese que solo concibiendo los precedentes de este modo es posible dar cuenta de los problemas de interpretación de las decisiones jurisdiccionales. 
frente a una decisión que cuenta como precedente, toda vez que haya otra norma que indique que aquella es un precedente: la regla del stare decisis.

Si bien no es el lugar indicado para desarrollarlo con toda la atención requerida, es preciso señalar que mi definición presupone una definición amplísima de “jurisdicción”, que no requiere de nada más para calificar una decisión como "jurisdiccional” que aquella sea dictada para resolver un caso (genérico o individual) basado en normas previamente establecidas de carácter no meramente procedimental, y a las que el ordenamiento atribuye algún valor normativo ${ }^{19}$. Desde luego, el caso paradigmático serán las sentencias judiciales acerca de una controversia que resuelve el fondo de un caso individual, pero incluye extensionalmente otras muchas cosas.

Comprende, en primer lugar, decisiones judiciales que resuelven (califican normativamente) tanto casos individuales como casos genéricos como, por ejemplo, las sentencias producto de los controles en abstracto de constitucionalidad de las leyes; en segundo lugar, incluye además las decisiones de carácter judicial diferente de la sentencia, como la admisión a trámite; en tercer lugar, incluye también decisiones de órganos de carácter no judicial, como órganos administrativos o árbitros; en cuarto lugar, decisiones de órganos jurisdiccionales de otros ordenamientos, tanto internacionales como nacionales; y por último, engloba también las decisiones de órganos cuyas decisiones no tienen fuerza ejecutiva, como las de algunos órganos consultivos.

El concepto de precedente aquí propuesto excluye, no obstante, al menos dos cosas. En primer lugar, deja afuera aquellas normas que no son formuladas o aplicadas en el marco de un procedimiento dirigido a la resolución de un caso individual o genérico, como por ejemplo las decisiones legislativas ${ }^{20}$. En segundo lugar, deja también fuera la norma individual dictada por el órgano jurisdiccional porque tal fenómeno recae en otra categoría, como la extensión de los efectos de la sentencia, como veremos un poco más adelante.

Este concepto amplio de precedente permite también salvar, dicho sea de paso, una objeción que tradicionalmente se dirige contra toda teorización del precedente desde el ámbito del civil law ${ }^{21}$. En efecto, frecuentemente se afirma que no es posible construir una única teoría del precedente judicial, debido a que las diferencias entre common law y civil law son demasiado importantes. Más allá de que ambos ordenamientos se han acercado mucho en las últimas décadas ${ }^{22}$, lo cierto es que la noción de precedente apenas delineada permite hacerse cargo del fenómeno de los precedentes en ambos contextos jurídicos debido precisamente a la amplitud de la definición de "precedente".

${ }^{19}$ No me estoy refiriendo a nada diferente a lo que hacen los órganos de adjudicación según Hart. Véase Hart, H.L.A., El concepto de derecho, Buenos Aires, Abeledo-Perrot, 2004, pp. 120-121

${ }^{20}$ No obstante, es preciso señalar que algunos autores han señalado la posibilidad de considerar algunas decisiones parlamentarias como precedentes. Lupo, N. (ed.), Il "precedente" parlamentare tra diritto e politica, Il Mulino, Bologna, 2013.

${ }^{21}$ Para una respuesta más elaborada acerca del tema, véase Bustamante, Th., Teoría del precedente judicial, Legales Ediciones, Lima, 2016, cap. 1.

22 Barberis, M., Europa del diritto, Il Mulino, Bologna 2008, cap. III. 


\section{Precedentes y Fuentes Del DeRECho EN EL CIVIL LAW}

Además de que ambos tipos de ordenamientos se habrían acercado en los últimos decenios, y que el concepto de precedente delineado en el apartado anterior permite estudiar tal fenómeno en ambos tipos de ordenamientos, queda aún una duda acerca de la factibilidad de hablar de precedentes en el ámbito del civil law. Ello por la sencilla razón de que casi ningún ordenamiento del ámbito del civil law enumera, entre sus fuentes del derecho, los precedentes (o la jurisprudencia).

Sin embargo, aunque prácticamente ningún ordenamiento considera los precedentes como fuentes del derecho, la realidad es tozuda: los jueces siguen empleando decisiones pasadas para justificar sus decisiones, los abogados continúan empleándolas como argumentos persuasivos, las revistas de derecho siguen teniendo secciones específicas dedicadas al comentario de jurisprudencia, y se prosiguen pagando costosas bases de datos para mantenerse al día en lo que a la actualidad jurisprudencial se refiere ${ }^{23}$. De manera un poco inocente, podría preguntarse si toda esta gente está equivocada, o si por el contrario sea una mala idea afrontar el problema de los precedentes mediante la teoría de las fuentes del derecho. Y es que abordar el tema de los precedentes, al menos desde el punto de vista de la teoría normativa ${ }^{24}$ de las fuentes del derecho, no resulta conveniente, por dos diferentes razones.

En primer lugar, la noción de fuente es, como es bien sabido, tremendamente ambigua. Pese a que algunos autores hayan calificado como transparente esta metáfora ${ }^{25}$, es cualquier cosa menos claro qué son y, sobre todo, cuáles son las fuentes del derecho. Como es bien sabido, dentro de las fuentes del derecho suelen establecerse múltiples distinciones, dando lugar a fuentes formales, materiales, extra-ordinem, normativas, legales, auxiliares, y algunas más que no es preciso señalar. El problema surge porque difícilmente se puede sostener que el término "fuente" signifique lo mismo toda vez que se ve acompañada de cada uno de los adjetivos mencionados anteriormente.

En segundo lugar, el problema más grave que una aproximación por medio de la teoría normativa de las fuentes del derecho debe afrontar es que aquella suele resolverse en la pregunta acerca de si los enunciados normativos del propio ordenamiento que

${ }^{23}$ Esto no significa que tengamos que dar por buena la reconstrucción que los operadores jurídicos realizan acerca de lo que ellos mismos supuestamente harían cuando emplean decisiones jurisdiccionales pasadas para justificar decisiones posteriores. Lo que sí implica es que tenemos que hacernos cargo de qué es lo que realmente hacen, y no de lo que dicen que hacen, en la tradición empirista del realismo jurídico estadounidense. Véase Llewellyn, K., "Some realism about realism. Responding to Dean Pound”, Harvard Law Review, 44, p. 1237.

${ }^{24}$ Es posible preguntarse si una teoría meramente empírica de las fuentes del derecho constituiría una mejor forma de abordar la cuestión de los precedentes. La respuesta, aunque no puede ser desarrollada aquí con la debida profundidad, es afirmativa. Debo agradecer a Josep Aguiló, Diego dei Vecchi e Isabel Lifante, quienes me hicieron pensar un poco más respecto de este punto. Véase, en cualquier caso, Ross, A., Sobre el derecho y la justicia, Buenos Aires, Eudeba, 1997; id. Teoría de las fuentes del derecho, CEPC, Madrid, 2008. Véase también Barberis, M. "Para una teoría realmente realista del derecho", en Revus, 29, 2016.

${ }^{25}$ Guastini, R., La sintaxis del derecho, Marcial Pons, Madrid, 2016, p. 111. 
enumeran sus fuentes contemplan o no al precedente entre ellas. Dicha aproximación ha de rechazarse, por dos razones.

i) Las listas de fuentes formales del derecho reproducen una típica dificultad de la equivocidad de los textos normativos: no se puede establecer jurídicamente si tal lista es meramente ejemplificativa o taxativa ${ }^{26}$.

ii) Está basada en una concepción radicalmente formalista del derecho que hoy es mayoritariamente rechazada, porque implicaría afirmar que normas implícitas formuladas por doctrina y jurisprudencia no forman parte del derecho, pese a ser permanentemente usadas por todos los operadores jurídicos.

Aquí se afrontará la cuestión desde una perspectiva diferente, basados precisamente en lo que ya sabemos acerca de los diferentes grados de relevancia normativa de los precedentes. En particular, podemos identificar como criterio para la existencia de precedentes en un ordenamiento que aquellos se han tenido en cuenta como razones para la justificación de una decisión; es decir, se trata de un criterio empírico en la medida en que la presencia de un sistema de precedentes dependerá de si los operadores jurídicos emplean aquellos como razones a la hora de justificar sus decisiones. Sin embargo, el que hemos identificado como grado mínimo de vinculatoriedad-que se considere una razón válida o argüible frente a un tribunal- puede resultar, por un lado, demasiado poco para considerar que estamos frente a un genuino sistema de precedentes y, por el otro, que es difícilmente comprobable, ya que hay sistemas en los que son perfectamente alegables durante un proceso judicial razones que de ningún modo formarían parte del derecho (religiosas, políticas, de eficiencia, etc.). De este modo, los precedentes serían indistinguibles de las normas de otros conjuntos normativos que pueden ser alegados frente a un tribunal, pero que no consideraríamos como normas jurídicas. Si este es el caso, y así parece ser, no se podría concluir válidamente que hay un sistema de precedentes por el mero hecho de que estos sean alegables en sede jurisdiccional en un determinado ordenamiento.

Más allá de la plausibilidad de estas objeciones, es posible y recomendable ofrecer una tesis alternativa, no susceptible de ninguna de las críticas señaladas en el párrafo anterior. Para explicar este siguiente grado de vinculatoriedad de los precedentes es conveniente recurrir a la noción de relevancia normativa 2, desarrollada por Alchourrón y Bulygin $(\mathrm{A} \& \mathrm{~B})$ en Sistemas normativos ${ }^{27}$. En efecto, para ambos autores una propiedad puede tener relevancia normativa en tres diferentes sentidos. En primer lugar, para $A \& B$ una propiedad tiene relevancia cuando se la emplea como parte del universo de propiedades de un microsistema normativo (relevancia 1). En segundo lugar, para $A \& B$ una propiedad tendrá relevancia normativa cuando su presencia o ausencia en un caso implica, dentro de un determinado sistema normativo (permaneciendo constantes el resto

\footnotetext{
${ }^{26}$ Guastini, R., Interpretar y argumentar, CEPC, Madrid, 2014, pp. 59-60.

${ }^{27}$ Alchourrón C. y Bulygin, E., Sistemas normativos, Buenos Aires, Astrea, 2015, pp. 149-151.
} 
de propiedades), la modificación de la calificación que recibe el mismo caso (relevancia 2). En tercer lugar, para $\mathrm{A} \& \mathrm{~B}$ una propiedad tiene relevancia normativa si a partir de ella podemos colmar una laguna normativa en el sistema (relevancia 3).

Aquí únicamente me interesa la relevancia normativa 2. Pues bien, es posible afirmar que tenemos un sistema de precedentes al menos allí donde -toda vez que aparezcan dos decisiones judiciales alternativas (D1 y D2) prima facie igualmente justificadas- la alegación de un precedente en favor de D1 haga que se considere que está mejor o mayormente justificada que D2 (la decisión jurisdiccional no apoyada por ningún precedente) ${ }^{28}$, 29. Siendo este el grado mínimo de vinculatoriedad para poder hablar sensatamente de sistemas de precedentes, mediante este criterio empírico es posible dar cuenta de los diferentes sistemas de precedentes, tanto en el civil como en el common law, mostrando sus diferencias y similitudes.

De este modo, tendremos un sistema con precedentes normativos al menos allí donde el hecho de que la norma de origen jurisprudencial esté dotada de relevancia normativa 2 por razón de su origen y no de su contenido, constituyendo así una norma dotada de autoridad normativa ${ }^{30}$ (en el sentido precisado: independencia respecto del contenido $^{31}$ ). Esta forma de entender la vinculatoriedad de los precedentes permite dar cuenta de la heterogeneidad del fenónomeno del uso de precedentes, tanto de los sistemas de common como de civil law, en los que los precedentes pueden tener diferentes grados de vinculatoriedad, estableciendo un grado mínimo que permite, pese a las diferencias, reconocer cuándo estamos frente a un sistema de precedentes ${ }^{32}$.

\section{Precedentes en materia de hechos}

Una vez realizada esta apretada síntesis acerca de qué son los precedentes y cuándo estamos frente a un sistema jurídico con precedentes, es preciso ocuparse de la posibilidad

\footnotetext{
${ }^{28}$ Respecto de la consideración de la ratio decidendi como norma dotada de autoridad, véase en cualquier caso Duxbury, N., The Nature and Authority of Precedent, Cambridge University Press, 2008.

${ }^{29}$ En un sentido similar, véase Schauer, F., Pensar como un abogado, Marcial Pons, Madrid, 2013, caps. III y IV.

${ }^{30}$ Acerca de la consideración de la ratio decidendi como norma dotada de autoridad, véase en cualquier caso Duxbury, N., The Nature and Authority of Precedent, Cambridge University Press, 2008.

31 Esto quiere decir que para que una norma cuente como (ratio decidendi de un) precedente no es relevante cuál sea el contenido de la norma, sino quién la ha dictado. Ahora bien, por supuesto su contenido se vuelve del todo relevante a la hora de emplear el precedente para justificar una decisión posterior.

${ }^{32}$ Un evaluador anónimo de este trabajo, a quien le estoy agradecido por sus interesantes comentarios, me señala que esta forma de entender los precedentes dejaría de lado aquello que es "definitorio" de los precedentes. El problema de este tipo de posiciones parte, en mi opinión, de dos consideraciones: en primer lugar, pensar que hay algo "definitorio" de los precedentes, lo que me parece que refleja una posición algo esencialista; en segundo lugar, no creo que esté justificado pensar que tal elemento definitorio depende de una determinada reconstrucción de la práctica del precedente en el common law. Cómo sea la práctica de los precedentes en Estados Unidos es en realidad una cuestión controvertida. Véase, por ejemplo, Magaloni, A. N., El precedente constitucional en el sistema jurídico norteamericano, McGraw-Hill, Madrid, 2001.
} 
de hablar sensatamente de precedentes en materia de hechos ${ }^{33}$. Ello porque surgen múltiples dudas acerca de la posibilidad de tan siquiera pensar en precedentes en materia de hechos. La primera de ellas es que, si hemos definido ratio decidendi como norma empleada en la justificación interna o externa de una decisión jurisdiccional (y dotada de valor vinculante para casos futuros), los hechos no son normas, sino eventos o acciones del mundo real. Ahora bien, aquello que es objeto de prueba no son exactamente los hechos, sino enunciados acerca de determinados hechos. Sin embargo, al tratarse de enunciados descriptivos, esto todavía no habilita para hablar de precedentes en materia de hechos.

Antes de poder explicar cómo es posible hablar de precedentes en materia de hechos de manera sensata, es necesario introducir algunas distinciones. En el presente apartado procederé del siguiente modo. En primer lugar, daré cuenta de una ambigüedad de la que padece la expresión "hecho probado". Ello me permitirá, en segundo lugar, dar cuenta de cómo, o en qué sentido, es sensato hablar de precedentes en materia de hechos.

\section{1. "Hechos probados": una ambigüedad}

La expresión "hechos probados" padece de una ambigüedad similar a la clásica ambigüedad proceso-producto. En efecto, cuando nos referimos a ciertos hechos como "probados", podemos estar haciendo referencia a dos cosas diferentes: en primer lugar, que los hechos han sido objeto de un proceso probatorio, razón por la que se considera como verdadero el enunciado descriptivo que los refiere; y, en segundo lugar, que -en la medida en que han sido sometidos a un procedimiento probatorio- aquellos gozan de reconocimiento institucional. Sin embargo, como es bien sabido, en ocasiones determinados enunciados acerca de los hechos gozan de reconocimiento institucional sin que hayan sido objeto de un proceso probatorio o sin que necesariamente se consideren como verdaderos.

Se trata, como parece evidente, de dos sentidos diferentes de "hechos probados": en el primer sentido, hacemos referencia a un enunciado que da cuenta de un determinado hecho que ha sido sometido a un procedimiento probatorio y que es considerado verdadero; en el segundo, nos referimos a que el ordenamiento considera determinados enunciados descriptivos sintéticos como enunciados institucionalmente reconocidos. Es decir, en el primer caso estamos afirmando que un enunciado sometido a un proceso probatorio es verdadero (actividad probatoria); en el segundo caso se le atribuye una propiedad institucional a un determinado enunciado descriptivo (resultado institucional). Tal propiedad institucional consiste en que el enunciado puede ser empleado en la justificación de la decisión jurisdiccional.

De este modo, conviene distinguir entre dos aspectos diferentes en relación con la expresión "hechos probados":

33 Por "hecho" o "hechos" estoy entendiendo -siguiendo a González Lagier, quien toma la noción de Russell- simplemente aquello que hace verdaderos o falsos a nuestras proposiciones o creencias. Véase González Lagier, D., Quaestio Facti, México, Fontamara, 2013, p. 7. Agradezco a Daniel González Lagier por haberne señalado esta idea. 
a) El primer aspecto hace referencia al hecho de que un determinado enunciado relativo a hechos individuales ha sido objeto de un proceso probatorio, y se considera que dicho enunciado es verdadero.

b) El segundo aspecto hace referencia a un determinado resultado institucional: la atribución a dicho enunciado de la propiedad de ser fundamento válido (condición de validez) para una decisión jurisdiccional.

Como parece evidente, estos dos aspectos pueden darse de manera independiente. Es posible, en primer lugar, que un determinado enunciado haya sido sometido a un procedimiento probatorio y sea verdadero, pero no se le atribuya reconocimiento institucional alguno (por ejemplo, porque ha sido demostrado en violación del derecho probatorio); y, en segundo lugar, es posible que se atribuya dicha propiedad institucional a un enunciado acerca de los hechos sin que se haya producido ningún proceso probatorio al respecto, e incluso se considere que el enunciado que da cuenta del hecho individual es falso ${ }^{34}$ (o nos dé igual si es verdad o no ${ }^{35}$ ).

Para poder comprender cómo los hechos pueden ser objeto de precedentes (o al menos, uno de los sentidos en los que es posible hablar de precedentes en materia de hechos), es preciso desentrañar este último sentido: enunciados (descriptivos) reconocidos institucionalmente por el derecho. En efecto, si bien los enunciados que consideran como probados determinados ciertos hechos tienen como dirección de ajuste la realidad empírica (teniendo valores de verdad), lo cierto es que el hecho de que una autoridad normativa -judicial o legislativa- califique un hecho como "probado" (en el segundo sentido) hace que el enunciado que lo refiere deje de ser un enunciado descriptivo como otro cualquiera, por dos razones:

i) En primer lugar, cuando en el ámbito jurídico se afirma que un hecho está probado no se está queriendo decir necesariamente que aquel que lo expresa es un enunciado verdadero. Por el contrario, se puede estar afirmando tanto que se considera verdadero dicho enunciado (primer sentido) como que existen razones jurídicas suficientes para considerarlo como verdadero (segundo sentido). Y decir que hay razones suficientes para considerarlo probado en el segundo sentido constituye el resultado de la aplicación de varias normas -al menos- sobre la admisión, la valoración y el estándar de prueba.

ii) En segundo lugar, porque es posible considerar como justificada (condición de su justificación) una decisión solo en el caso de que la premisa fáctica de la decisión judicial sea el resultado de la aplicación de las reglas de la prueba ${ }^{36}$. Es decir, si

${ }^{34}$ Piénsese, por ejemplo, en una presunción iuris et de iure, en el que se demuestra como verdadero el antecedente de la presunción, pero se sabe que el consecuente es, para el caso individual, falso.

35 Por ejemplo: en los ordenamientos de nuestro entorno no se admite prueba en favor del consentimiento sexual de menores por debajo de una determinada edad.

${ }^{36}$ Esto parecería contar como un argumento en favor de la tesis kelseniana en donde la premisa menor del silogismo judicial no es un enunciado acerca de los hechos, sino lo que aquí llamaré un enunciado 
una decisión jurisdiccional está basada en un enunciado verdadero (probado en el primer sentido) pero que ha violado las reglas jurídicas de la prueba -como, por ejemplo, cuando se ha obtenido una declaración del inculpado torturándole- se considerará no probado en el segundo sentido, y la decisión inválida. Y al contrario: podría ser válida la decisión jurisdiccional que utiliza una premisa fáctica falsa pero que constituye el resultado del procedimiento probatorio.

Pero si así están las cosas, y el enuncado probatorio constituye la aplicación de las reglas del derecho probatorio, entonces parece que el resultado del razonamiento probatorio no es exactamente un enunciado de carácter descriptivo, sino más bien un enunciado que expresa una norma constitutiva de carácter individual ${ }^{37}$ que parafrasea el enunciado descriptivo. En su formulación canónica: "El enunciado y según el cual 'está probado X' forma parte de los enunciados institucionalmente reconocidos por el derecho”.

De este modo, es necesario distinguir con precisión entre el enunciado descriptivo sintético que versa acerca de la realidad del mundo (enunciado de hechos con valores de verdad), por un lado, de aquel enunciado que considera un determinado hecho como probado (enunciado calificatorio con valores de validez e invalidez), por el otro ${ }^{38}$. En

calificatorio individual. En caso contrario, nos veríamos obligados a afirmar que una decisión basada en un enunciado verdadero, pero que es el producto de un razonamiento probatorio en el que se han obtenido pruebas en violación de normas de la prueba -por ejemplo, de derechos humanos- es una decisión válida. Sin embargo, mi trabajo no está comprometido con la tesis kelseniana, ni para aceptarla ni para rechazarla. Acerca de la tesis de los enunciados probatorios kelsenianos, véase Dei Vecchi, D., "Acerca de la fuerza de los enunciados probatorios: el salto constitutivo", en Doxa, vol. 37, 2014.

${ }^{37}$ Por "norma constitutiva" entiendo sencillamente aquella norma que considera que una determinada entidad, caso u objeto forma parte de una clase o categoría, es decir, una norma que correlaciona un caso con otro caso, estableciendo así una relación de inclusión. Cfr. Moreso, J. J., y Vilajosana, J. M., Introducción a la teoría del derecho, Marcial Pons, Madrid, 2004, p. 74.

Con certeza, Moreso y Vilajosana conciben las normas constitutivas como normas que correlacionan casos genéricos con otros casos genéricos. No obstante, nada parece impedir pensar en normas constitutivas individuales que correlacionen casos individuales con casos genéricos, del mismo modo que aceptamos la existencia de normas prescriptivas individuales que correlacionan casos individuales con operadores deónticos. Si se acepta la existencia de normas prescriptivas individuales, no parece haber razón para no admitir la existencia de normas constitutivas individuales.

38 Algunos autores llaman al primero enunciado sobre hechos, mientras que al segundo lo llaman enunciado probatorio. Sin embargo, debido a la ambigüedad anteriormente analizada prefiero evitar la denominación "enunciado probatorio".

Me señalan Carmen Vázquez, Daniela Accatino y Diego dei Vecchi que la expresión "enunciado calificatorio" genera otra ambigüedad, ya que normalmente se emplea para referirse al enunciado que subsume al enunciado fáctico token en el supuesto de hecho de una norma, es decir, califica jurídicamente un caso individual ("Juan cometió asesinato"). Sin embargo, aquí no hay ambigüedad alguna porque lo que estoy sosteniendo es precisamente que el enunciado que sostiene que, para el derecho, un enunciado descriptivo está reconocido ("está probado que sucedió X"), es un enunciado precisamente de este tipo, que constituye la conclusión de un razonamiento probatorio cuya parte final es un silogismo en el que se dispone que está calificado jurídicamente un enunciado respecto de los hechos. Asumo aquí parcialmente la terminología propuesta por Rafael Hernández Marín a lo largo de su obra. Nada de lo anterior obsta para que haya que distinguir detalladamente entre el enunciado interpretativo en concreto que califica el caso sub judice, y el 
efecto, mientras que la formulación canónica del enunciado de hechos reza "Ha sucedido el evento X", el enunciado calificatorio responde, en su forma abreviada, a la forma "Está probado que X".

Este último tipo de enunciado calificatorio puede ser traducido, sin pérdida de significado, al enunciado en el que “'ha sucedido el evento $\mathrm{X}$ ' forma parte del conjunto de enunciados institucionalmente reconocidos por el derecho, siendo de este modo válida (condición de validez de) la decisión judicial que en aquel se fundamenta”. El enunciado calificatorio, antes que ser meramente un enunciado de carácter descriptivo, es un enunciado que expresa una norma constitutiva, y que considera un determinado enunciado descriptivo sobre hechos (sobre un caso individual) como parte de los enunciados reconocidos en el ámbito jurídico ${ }^{39}$.

El enunciado calificatorio individual resultado de un procedimiento probatorio es una norma constitutiva de carácter individual, es decir, se habrá llevado a cabo un procedimiento probatorio que justifique la adopción de tal enunciado calificatorio y además se considere verdadero. Sin embargo, para seguir avanzando es necesario subrayar que es perfectamente posible, como ya hemos visto, que el ordenamiento jurídico atribuya reconocimiento institucional a enunciados que no han sido de ningún modo sometidos a un proceso probatorio o no se consideren verdaderos.

Por ejemplo, es perfectamente posible que el ordenamiento considere como probado que las mujeres tienen menores capacidades intelectuales, que los inmigrantes musulmanes abusan más de las mujeres, que los menores de 12 años nunca tienen capacidad para consentir relaciones sexuales o cosas parecidas. Es decir, el ordenamiento jurídico puede contener cualquier tipo de enunciado calificatorio (que expresa una norma individual) acerca de hechos que sirvan para tomar decisiones justificadas desde el punto de vista jurídico. Cuando dichos enunciados son formulados en decisiones jurisdiccionales, entonces nos encontraremos con nuestros principales candidatos para ser precedentes en materia de hechos.

\section{Enunciados individuales sobre hechos vs. generalizaciones sobre bechos}

Sin embargo, puede resultar aún extraño afirmar que un enunciado calificatorio individual en materia de hechos pueda constituir un precedente: si los enunciados calificatorios acerca de hechos son enunciados sobre hechos individuales, resulta difícil

enunciado -en la terminología aquí adoptada-calificatorio que considera probado el hecho. Y, en el fondo, no se trata nada más que de una cuestión de etiquetas.

${ }^{39}$ Daniel González Lagier, y un evaluador anónimo de este trabajo, han señalado que no bastaría con una subsunción individual para que haya norma constitutiva (individual). Sin embargo, ello depende de una determinada concepción acerca de la existencia de normas y de los sistemas normativos. El problema es que esta posición parecería estar rechazando (implícitamente) el carácter estático de los sistemas normativos, en lo que las consecuencias lógicas de las normas son también normas. No parece ser este el lugar indicado para discutir la cuestión, pero si aceptamos que las consecuencias lógicas de las normas son también normas (y no proposiciones), entonces este producto de la aplicación de las normas del derecho probatorio también serían normas, véase Caracciolo, R., "Existencia de normas”, en Isonomía, 7, 1997. 
imaginar cómo es posible que aquellos puedan ser empleados en un caso posterior en el que, efectivamente, se juzgan otros hechos.

En efecto, enunciados probatorios individuales no pueden ser considerados precedentes. Ello, no obstante, no implica que no puedan ser considerados como enunciados vinculantes en otros procedimientos jurisdiccionales. De hecho, esto es lo que normalmente sucede cuando se interpone un recurso en el que se precluye la posibilidad de fijar nuevamente o revisar los hechos del caso: el tribunal que conoce de dicho recurso normalmente está vinculado por el enunciado calificatorio respecto de los hechos.

Pero no es este el único caso en el que puede suceder que el enunciado calificatorio individual tenga valor vinculante. Es posible que en el transcurso de un proceso judicial se fijen hechos -es decir, se produzcan enunciados calificatorios sobre hechos- que van más allá del caso individual que está siendo juzgado. Por ejemplo, es perfectamente posible que, en el desarrollo de un procedimiento jurisdiccional en el que un usuario de una tarjeta de crédito demanda a la empresa emisora de la tarjeta por subir los costes de la misma sin aviso, se establezca que todos quienes contrataron un servicio de tarjeta de crédito con esa misma empresa comercial en el mismo período sufrieron un aumento de los costes de la tarjeta. Esto es, el tribunal produce enunciados calificatorios acerca de hechos individuales que no son, en rigor, objeto del proceso.

Ahora bien, no parece que aquí podamos hablar de precedentes en materia de hechos. Por el contrario, si se atribuye valor a estos enunciados calificatorios por hechos individuales en procesos futuros, parece que estaríamos más bien frente a la extensión de la eficacia de la sentencia en relación con los hechos, expandiendo los efectos de la decisión individual de los hechos a otros procesos ${ }^{40}$. Pero no es únicamente el enunciado calificatorio individual producido en el proceso el que no puede convertirse en precedente: ningún enunciado individual se convierte en precedente, aunque verse pertinente a hechos diferentes a aquellos en los que recae la sentencia. Ello no se debe a alguna imposibilidad práctica o teórica, sino sencillamente a que en nuestros ordenamientos jurídicos normalmente se califica de manera diferente ambas situaciones, considerándose este caso como una extensión de los efectos de la sentencia (aunque sea solo en relación con los hechos).

Para explicar esta última idea es conveniente retomar el discurso general acerca del precedente. En efecto, nadie sostiene que objeto del precedente sea la norma individual del caso que califica jurídicamente el caso concreto, si bien aquella puede ser empleada en la justificación de otra decisión jurisdiccional. Por ejemplo, sería perfectamente posible que, en procesos de consumo, si se ha dictaminado en una causa previa que una

${ }^{40}$ En muchos ordenamientos no es posible la extensión de la eficacia de la decisión relativo a los hechos a sujetos que no han sido parte del proceso. Sin embargo, lo que me interesa señalar no es tanto el contenido de ningún concreto ordenamiento, sino bajo qué figura recaería si se decidiera dar valor a enunciados calificatorios individuales respecto de sujetos que no fueron parte del proceso. El enunciado típico en este contexto es el enunciado individual que versa para todos los sujetos de un grupo en un proceso en el que no todos los miembros de dicho grupo forman parte del procedimiento. Véase, en cualquier caso, Romero Seguel, A., "La sentencia judicial como medio de prueba", ob. cit. 
determinada práctica llevada a cabo por una empresa es contraria a los derechos de los consumidores, y se plantease una nueva causa por parte de un sujeto que no fue parte en el primer proceso, no se entra a valorar nuevamente si la práctica de la empresa es contraria al derecho de los consumidores, sino que directamente se considera que dicha práctica es contraria a derecho. Pero aquí parece que estamos ante la extensión de los efectos de la sentencia, no frente a un precedente.

Algo parecido puede suceder en materia de hechos toda vez que el enunciado calificatorio, si bien tiene carácter individual, incorpora afirmaciones sobre hechos diferentes a aquellos que son objeto del proceso. El caso más evidente es cuando se realizan enunciados calificatorios individuales sobre un grupo de sujetos, no siendo ni todos sus miembros, ni la colectividad en cuanto tal, parte del proceso.

No se trata, sin embargo, únicamente de un diferente reconocimiento del que gozarían ambos tipos de enunciados: tienen diferente reconocimiento institucional -extensión de los efectos de una parte de la sentencia y valor de precedente- porque se trata de enunciados de carácter diferente. Es preciso distinguir en este sentido entre el enunciado calificatorio individual que da cuenta de que un hecho ya ha sucedido ("quienes contrataron con el sujeto x tuvieron que pagar más por el producto contratado”), del enunciado general que atribuye determinadas propiedades no contrastables a un grupo de sujetos ("todas las mujeres sufren depresión postparto”), lo que no es otra cosa que una generalización.

La diferencia entre ambos tipos de enunciados no pasa por la cantidad de sujetos sobre los que se predica una cierta cualidad, sino sobre el contenido proposicional que transmiten ambos enunciados. Mientras que los primeros se refieren a hechos ya acaecidos, los segundos atribuyen una determinada cualidad a un conjunto de sujetos que no puede ser verificada al momento actual en todos los miembros del grupo: son la conclusión de razonamientos inductivos (más o menos racionales o justificados), empleados para realizar predicciones acerca del futuro ${ }^{41}$. Por ejemplo, no es posible constatar que todas las mujeres tienen depresión postparto, sencillamente porque no todas las mujeres acaban de dar a luz, ni todas están embarazadas, ni todas van a estarlo.

Nótese que ambos tipos de enunciados ("quienes contrataron con el sujeto x tuvieron que pagar más por el producto contratado" y "todas las mujeres sufren depresión postparto") pueden gozar de la propiedad de ser reconocidos por el derecho. Ahora bien, como veremos enseguida, la generalización raramente será ella misma objeto de prueba, aunque un tribunal decida adoptarla, dotándola así de reconocimiento institucional. Pero, si así están las cosas, entonces ha de señalarse que lo que dota de reconocimiento institucional a un enunciado general no es necesariamente que aquel haya sido objeto de un proceso probatorio; más bien, un enunciado de este tipo puede gozar de reconocimiento institucional sin necesidad de que sea sometido a un procedimiento probatorio. En efecto,

41 Nótese que dicha generalización puede estar más o menos justificada desde el punto de vista epistémico. Pero, además, en la justificación de dichas generalizaciones pueden jugar un papel importante razones no epistémicas, sino ético-políticas o morales en sentido amplio. Este sería el caso, por ejemplo, cuando se considera que ningún menor de 12 años puede dar consentimiento para mantener relaciones sexuales. 
del mismo modo que una generalización puede ser formulada por el legislador, puede también estar contenida en una decisión jurisdiccional y convertirse así en ratio decidendi.

El precedente no versa ni sobre normas individuales ni sobre enunciados probatorios individuales, sino sobre normas generales y enunciados generales. Cuando lo que tenemos es que el ordenamiento reconoce a normas y enunciados individuales, entonces parece más conveniente calificarlo como extensión de los efectos de la decisión jurisdiccional; cuando lo que tenemos son enunciados de carácter general, entonces podemos hablar propiamente de precedentes.

\section{Dos TIPOS DE PRECEDENTES EN MATERIA DE HeChOS}

En el presente apartado analizaré qué tipos de precedentes en materia de hechos es posible encontrar en el derecho. Para ello es conveniente retomar la distinción introducida cuando se dio cuenta de la ambigüedad de la que padecía la expresión "hechos probados". En efecto, dicha expresión puede hacer referencia tanto a que determinados hechos han sido objeto de prueba (y se consideran verdaderos), como que aquellos -el enunciado que da cuenta de ellos- gozan de reconocimiento por parte del derecho.

Ahora bien, no se trata, como ya sabemos, de que todos los hechos -los enunciados que dan cuenta de esos hechos- que gozan de reconocimiento por parte del derecho sean el producto de una actividad probatoria, sencillamente porque en ocasiones se les reconoce valor sin que se haya producido actividad probatoria en su sustento. Junto con este tipo de enunciados, el derecho regula -o puede regular- mediante precedentes también la forma en la que ha de ser llevada a cabo la actividad probatoria (o a qué resultado probatorio se ha de llegar). Llamaré a los primeros "precedentes sobre hechos en sentido estricto", mientras que a los otros lo denominaré "precedentes probatorios" 42 .

\section{Precedentes sobre bechos en sentido estricto: enunciados calificatorios generales}

Ya sabemos (supra 3.2) que pueden ser precedentes enunciados que expresan generalizaciones, pero no enunciados calificatorios individuales, incluso aunque aquellos versen sobre una colectividad de sujetos. La diferencia entre ambos tipos de enunciados es que mientras que las generalizaciones no pueden ser verificadas, los enunciados

${ }^{42}$ No se trata de que confunda normas de derecho probatorio con enunciados de carácter general sobre hechos, como lo señala un evaluador, sino que al ser ambos tipos de precedentes relativos a la justificación de la premisa empírica en procesos posteriores, es posible agruparlos todos bajo una misma categoría de precedentes en materia de (o relativos a) hechos. 
individuales sobre hechos sí pueden ser verificados ${ }^{43}$ al referirse a hechos pasados ${ }^{44}$. Y, como también sabemos, los hechos a los que se refiere el enunciado general pueden o no haber sido objeto de prueba.

\subsection{Precedentes sobre hechos que no han sido objeto de prueba (en el proceso jurisdiccional)}

"Los niños que son educados en colegios que separan por sexos tienen problemas para relacionarse en la adolescencia", "los niños crecidos en familias monoparentales no tienen problemas de afectividad", "las campañas informativas sobre las consecuencias del consumo de tabaco reducen su consumo". Aunque ninguno de los tres enunciados anteriores son enunciados sobre hechos individuales, ni siquiera sobre conjuntos de hechos individuales, aquellos juegan un papel fundamental en el razonamiento probatorio, siendo en muchas ocasiones la premisa mayor de la justificación externa de la premisa fáctica del silogismo judicial. En muchas ocasiones, dichos enunciados generales están sustentados en pruebas llevadas a cabo en algún proceso jurisdiccional, pero lo cierto es que no siempre es así. Es posible distinguir al menos dos tipos de situaciones en este último caso.

i) En algunas ocasiones dicho enunciado es la conclusión de un razonamiento llevado a cabo por científicos, que realizan experimentos con el objetivo de contrastar su hipótesis. En tal caso, desde luego se producen pruebas, pero aquellas no se producen dentro del proceso ni tienen carácter jurídico, sino que son pruebas desarrolladas de manera independiente al proceso jurisdiccional.

Dentro de este primer tipo, es posible a su vez distinguir al menos entre tres diferentes tipos de enunciados sobre hechos. En primer lugar, nos encontramos con

43 Apuntan Daniel González Lagier y Diego dei Vecchi que, en realidad, en la mayoría de ocasiones los hechos pasados tampoco pueden ser verificados, y lo que pasa normalmente es que la prueba de dichos hechos se producen mediante el uso de generalizaciones producto de razonamientos inductivos. Sobre esto no parece que se pueda diferir. No obstante, si en la prueba de enunciados individuales se recurre a razonamientos inductivos es porque estamos ante lo que $\mathrm{A} \& \mathrm{~B}$ han llamado laguna de conocimiento. Ahora bien, parece que si idealmente dispusiéramos de toda la información relevante, tal enunciado individual podría ser verificado.

Sin embargo, en el caso de los enunciados que formulan generalizaciones las cosas son más complejas. El enunciado "todos los cisnes son blancos" es un enunciado ambiguo, ya que puede ser interpretado de dos modos diferentes: en primer lugar, puede ser interpretado como el enunciado en el que todos los cisnes que existen son blancos, siendo en este caso la verificación perfectamente posible, pero faltándonos información para hacerlo; en segundo lugar, el enunciado puede significar que todos los cisnes de hoy y los del futuro son blancos, pero en tal caso la verificación no es posible ni siquiera en los contextos en los que tenemos acceso idealmente a toda la información relevante. En tal sentido, mientras que los segundos enunciados expresan generalizaciones, los primeros son enunciados que engloban una cantidad enorme pero finita de casos.

${ }^{44}$ En la medida en que pueden ser verificados los hechos pasados. Aquí no estoy manteniendo una aproximación ingenua respecto de la prueba de hechos. Para estas dificultades, véase, por ejemplo, Frank, J., Derecho e incertidumbre, Fontamara, México, 2012. 
aquellos enunciados que constituyen la conclusión de investigaciones científicas que ya son aceptadas generalizadamente como tesis contrastadas. Esto es lo que en el ámbito de la teoría de la prueba, pero también del derecho procesal probatorio, se conoce como "conocimientos científicos afianzados". En segundo lugar, también nos podemos encontrar con enunciados generales que, si bien son la conclusión de razonamientos científicos, aquellos no forman parte aún del conocimiento científico afianzado, sino que son producto de la adopción de una posición por parte de los órganos jurisdiccionales acerca de una determinada tesis de carácter científico $^{45}$. En tercer lugar, los tribunales en ocasiones realizan afirmaciones acerca de hechos, que si bien no han sido comprobados científicamente -si presuponemos algún concepto exigente de "ciencia"- son tesis aceptadas de manera general por disciplinas como la historia o la economía ("el aumento del paro produce una constricción de la demanda interna", "no puede haber procesos de reconciliación nacional sin procesos de fijación de la verdad histórica" ${ }^{46}$.

ii) También es posible encontrar enunciados generales que no son el producto de ningún razonamiento probatorio, ni jurisdiccional ni científico. No obstante, esto no quiere decir que sean enunciados falsos o simplemente producto de prejuicios, o al menos no en todos los casos. Es posible, en este sentido, distinguir aquellos enunciados generales que dan cuenta de hechos, acciones o estados de cosas que, aunque no han sido objeto de prueba, gozan de un importante margen de aceptación (las así llamadas "máximas de la experiencia" como, por ejemplo, "las víctimas de violencia de género no denuncian al maltratador a la primera agresión”), por un lado, de aquellos enunciados que no son ni producto de ninguna prueba ni tampoco conocimientos generalmente aceptados ("una mujer no puede ser violada si viste pantalones vaqueros”), sino que más bien constituyen prejuicios.

45 En este sentido, es difícil exagerar la incidencia que tiene tener un smartphone con accesos a bases de datos, o a diferentes plataformas académicas: los jueces pueden realizar afirmaciones de carácter científico sobre temas altamente complejos al menos con un mínimo grado de respaldo. No hay duda de que diferentes ordenamientos obligan a los jueces acudir a peritos expertos para determinar la verdad (o plausibilidad) de determinados conocimientos, esto no implica que, en la práctica, los jueces no fijen hechos científicos por su cuenta ni que, posteriormente, aquellos no puedan convertirse en precedentes. Aquí de ningún modo estoy aceptando ni rechazando dicha práctica judicial, sino que únicamente estoy dando cuenta de ella.

46 Es factible, no obstante, imaginar también que enunciados parecidos a los anteriores, pero sobre hechos individuales, lleguen a tener valor de precedente. Por ejemplo: "la crisis económica mundial actual se debió a la burbuja del mercado hipotecario estadounidense" o "El 23F en España fue planeado solo por unos pocos y no gozaba de apoyo entre las más altas instituciones del Estado". Estos enunciados no constituyen generalizaciones pero, del mismo modo que aquellas, no son enunciados que puedan ser verificados, al menos en el sentido de verificación de las disciplinas científicas más exigentes. Por el contrario, estos enunciados son interpretaciones - entendidas como atribuciones de sentido- de diferentes hechos y acciones por parte de expertos en las respectivas disciplinas. 


\subsection{Precedentes sobre hechos que han sido objeto de prueba}

Es importante señalar que los enunciados generales sobre hechos no son, en sentido estricto, objeto de prueba, debido justamente a que aquello que puede ser objeto de prueba es un enunciado de carácter individual. Los enunciados generales, como ya sabemos, no pueden ser verificados, aunque sí falsificados. Por el contrario, lo que sí puede ser objeto de prueba es el conjunto de enunciados individuales a partir de los cuales se formula un enunciado de carácter general. En efecto, con frecuencia los tribunales profieren enunciados generales que constituyen la conclusión de un razonamiento de carácter inductivo que es llevado a cabo, basado en las pruebas aportadas por las partes, en el marco del procedimiento judicial.

Sin embargo, en algunas ocasiones lo que se convierte en objeto de proceso probatorio no es exactamente el enunciado general, sino una regla de inferencia entre dos enunciados generales que permite dar como probado el segundo enunciado cuando se da por probado el primero: esto es, las presunciones normativas ${ }^{47}$. En efecto, cuando estamos frente a una presunción normativa -cuya formulación canónica sería "si se prueba A, se puede (o se debe dar) por probado B"- estamos frente a tres elementos: el tipo de hecho que figura en el antecedente (A), aquel que figura en el consecuente (B), y la propia regla que permite dar por probado uno a partir del otro.

Nótese que cuando se emplea la presunción aquello que es objeto de prueba no es exactamente la descripción del tipo de hecho que figura en el antecedente de la presunción normativa (A), ni el que figura en el consecuente (B), ni la propia regla de inferencia. Lo que constituye objeto de prueba en el proceso en el que se aplica la presunción es un enunciado individual $\left(A_{1}\right)$ subsumible en el contenido proposicional que figura en el antecedente de la presunción (A).

Cuando estamos frente a la presunción en la que "se presume que adquirió de buena fe (B) el comprador que acudió al registro de la propiedad (o al conservador de bienes raíces) para conocer del estado de un predio (A)", tenemos dos descripciones sobre hechos: en primer lugar, acudir al conservador de bienes raíces (A) y, en segundo lugar, la adquisición de buena fe (B). Aquí, por consiguiente, lo que ha de ser objeto de prueba, cuando la presunción es empleada, no es el enunciado general "acudir al registro de la propiedad" $(A)$, sino más bien un enunciado individual en donde un determinado sujeto acudió al registro de la propiedad $\left(A_{1}\right)$. Este enunciado individual $\left(A_{1}\right)$, que es subsumible en el antecedente (A) de la norma que establece la presunción, es aquel que es objeto de prueba, y permite reconocer institucionalmente al enunciado individual $\left(\mathrm{B}_{1}\right)$

${ }^{47}$ No obstante, es preciso señalar que toda generalización puede ser reformulada como un enunciado condicional: "si una mujer lleva pantalones vaqueros, entonces no puede ser violada". Sin embargo, la conversión de las generalizaciones en enunciados condicionales produce algunos problemas. Véase Hospers, J., Introducción al análisis filosófico, Alianza, Madrid, 1982, pp. 293 ss. 
-subsumible en el tipo de hecho que aparece en el consecuente de la presunción (B)-, según este, un determinado sujeto actuó de buena $\mathrm{fe}^{48}$.

Ahora bien, lo que puede suceder es que, en un proceso anterior, en el que se estableciese la presunción en cuestión (adquiriendo valor de precedente), se haya realizado un proceso probatorio en el que se ofrecen razones -entre ellas, también de carácter probatorio- en favor de que toda vez que se dé por probado el acaecimiento de un hecho $A_{0}$ (instanciación del tipo de hecho que aparece en el antecedente de la presunción $A$ ), sea positivo (justo, racional, razonable, etc.) considerar como probado también el hecho $\mathrm{B}_{0}$ (instanciación del tipo de hecho que aparece en el consecuente $\mathrm{B}$ ). Dichas razones pueden ser tanto de carácter teórico como razones de carácter práctico ${ }^{49}$. Y es solo en este sentido que podemos considerar como objeto de prueba la presunción normativa en sí misma, y no el acaecimiento de hechos individuales subsumibles en el antecedente de la presunción.

\section{Precedentes probatorios: regulación de la actividad probatoria}

El caso probablemente más sencillo en el que pueden establecerse precedentes en relación con los hechos (en sentido amplio) es aquel de las normas relativas a la prueba ${ }^{50}$. Aquí no me voy a ocupar específicamente de todas las normas relativas a la prueba, lo que requeriría de un largo trabajo, diferente y autónomo respecto del actual. No obstante, sí es posible afirmar que cualquier norma en materia probatoria puede ser objeto de un precedente -reglas sobre inferencias, sobre el valor a atribuir a los testigos, sobre la exclusión de prueba, sobre el estándar de prueba, sobre cargas probatorias, etc.-, siempre que aquella venga a regular la actividad probatoria (o su resultado) y tenga origen en una decisión jurisdiccional.

Cuando se habla de precedentes, es frecuente introducir diferentes distinciones a base de su origen, a su fuerza, pero también respecto de su contenido. En este sentido, yo mismo he empleado anteriormente la distinción entre precedentes normativos, interpretativos y fácticos ${ }^{51}$. Sin embargo, esta distinción no resulta de demasiada utilidad si

${ }^{48}$ Un evaluador de este trabajo se pregunta cómo puede ser probada la buena fe. Aquí, sin embargo, lo que se prueba es un hecho individual, el que es subsumido en el antecedente de una presunción. Es una autoridad normativa quien fija presunciones de este tipo. Cosa distinta es el mérito o demérito de este tipo de operaciones, tanto si son establecidas por el legislador como si lo son por órganos jurisdiccionales.

49 Daniel González Lagier ha distinguido entre inferencias probatorias epistémicas e inferencias probatorias normativas: mientras que las primeras estarían sustentadas por razones teóricas, las segundas lo estarían por razones prácticas. Lo único que quiero señalar es que las razones que justifican la mayoría de nuestras presunciones pueden ser tanto de uno como de otro tipo. Cfr. González Lagier, D., "Hechos y conceptos", en Cuadernos electrónicos de filosofía del derecho, Vol. 15, 2007.

${ }^{50}$ Buenos ejemplos de precedentes probatorios en la jurisprudencia española pueden encontrarse en Fernández López, Mercedes, "La valoración de pruebas personales y el estándar de la duda razonable”, ob. cit.

51 Núñez Vaquero, A., "Sin precedentes: una mirada escéptica a la regla del stare decisis”, en Doxa, vol. 39, 2016, p. 137. 
nos centramos en los precedentes en materia probatoria, debido a la gran multiplicidad de tipos de precedentes que pueden darse en este ámbito.

Para abordar esta heterogeneidad es conveniente introducir una distinción ulterior, sobre la base de cómo son formulados. En términos generales, las reglas probatorias pueden formar parte del ordenamiento de dos maneras diferentes: en primer lugar, pueden ser sencillamente el producto de la interpretación de un enunciado normativo que pretende regular la actividad probatoria; pero pueden, en segundo lugar, ser el producto de actividades de construcción jurídica. No obstante, la diferencia entre unos y otros en la práctica puede ser tan difícil como preguntarse acerca de si una norma es producto de la interpretación o de construcción jurídica ${ }^{52}$.

La anterior no es, sin embargo, la única distinción relevante ni pertinente en materia de precedentes probatorios. En efecto, en teoría de la prueba es frecuente distinguir al menos entre dos momentos probatorios diferentes: i) la formación y aceptación de la prueba; ii) la valoración de la prueba individual y del estándar de prueba. Huelga decir que puede haber precedentes probatorios sobre cualquiera de los elementos que componen la regulación de la prueba.

Se trata, no obstante, de precedentes en relación con los hechos, ya que estos tienen relevancia a la hora de considerar como probados hechos en procesos jurisdiccionales. No hay duda de que no versan necesariamente de manera directa sobre algún hecho o tipo de hechos, parece sensato considerarlos como parte de la clase -más amplia- de los precedentes en materia de hechos.

\subsection{Precedentes probatorios interpretativos}

Estamos frente a un precedente interpretativo toda vez que un órgano jurisdiccional dicta o emplea una norma acerca de cuál debe ser la interpretación o cómo debe ser interpretado un enunciado normativo, y se reconoce valor vinculante a dicha interpretación a la hora de decidir otros casos. Consecuentemente, estaremos frente a un precedente probatorio de origen interpretativo toda vez que un tribunal fija cómo ha de ser interpretado un enunciado proveniente de una autoridad normativa que pretende dirigir el comportamiento en sede probatoria.

Esta actividad interpretativa a la que se le atribuye valor normativo es normalmente atribuida a los más altos órganos de cada ordenamiento. Sin embargo, es preciso señalar que nada impide que se reconozca valor de precedente a las decisiones jurisdiccionales de otros órganos, tanto con valor de precedente vertical (ascendente o descendente, entre órganos entre los que existe algún tipo de relación jerárquica), horizontal (entre órganos con competencias materiales iguales dentro de un mismo ordenamiento pero diferentes material o territorialmente), así como de autoprecedente (la decisión interpretativa es vinculante para un mismo órgano).

52 Este problema nos traslada a la cuestión acerca de los límites de la interpretación como atribución de significado, el que queda lejos de los objetivos de este trabajo y que, por tanto, no abordaré. 
No se debe olvidar, sin embargo, que el término "interpretación” padece también él de la clásica ambigüedad proceso-producto ${ }^{53}$. Conviene distinguir, en este mismo sentido, entre precedentes interpretativos que vienen a regular la actividad interpretativa de los enunciados en materia probatoria (regulación de la interpretación actividad), de aquellos que vienen a fijar directamente la interpretación producto a la que se debe llegar cuando se interpretan enunciados lingüísticos que pretenden orientar la actividad probatoria (regulación del resultado de la interpretación).

Un caso particularmente relevante sobre el que pocos han llamado la atención ${ }^{54}$ es cuando se dota de significado no exactamente a un enunciado normativo completo, sino únicamente a un término. Me refiero, en concreto, a la norma sobre la interpretaciónresultado dictada -0 acogida ${ }^{55}$ - por órganos jurisdiccionales que viene a definir cómo ha de ser empleado un término como, por ejemplo, acción, intención o causalidad. En este caso estaremos frente a una definición de origen jurisprudencial, que no es si no una norma constitutiva de carácter definitorio, y que perfectamente puede convertirse en precedente.

\subsection{Precedentes probatorios constructivos}

Sin embargo, sería ingenuo pensar que las únicas normas en materia probatoria formuladas y empleadas por los tribunales, y a los que se les reconoce valor vinculante para otros casos, son solo producto de la interpretación de enunciados normativos. Por el contrario, los tribunales con frecuencia llevan a cabo actividades que no pueden ser calificadas como interpretativas en sentido estricto, es decir, como actos de atribución de significado a enunciados normativos, y que tienen como resultado la producción de normas que regulan la actividad probatoria.

Riccardo Guastini, en relación con las actividades desarrolladas por la dogmática jurídica, ha dado cuenta de una multiplicidad de operaciones que tienen por objeto la derivación de normas implícitas mediante procedimientos lógicos (o no), bien partiendo de normas que pertenecen al ordenamiento, bien a partir de otras asunciones valorativas $^{56}$. Entre ellas, las principales son la creación de lagunas axiológicas (y las posteriores normas para colmarlas), la creación de principios implícitos y su eventual ponderación, la creación de jerarquías axiológicas entre normas y la resolución de antinomias. Ahora bien, las mismas operaciones pueden ser llevadas, y de hecho son llevadas, a cabo por parte de órganos jurisdiccionales.

${ }^{53}$ Guastini, R., "Interpretación y construcción jurídica”, en Isonomía, 43, 2015, p. 13.

54 González Lagier, D., "Hechos y conceptos", ob. cit.

55 Es perfectamente posible, y frecuente, que estas definiciones normativas sean formuladas en sede dogmática, y posteriormente acogidas (o reformuladas) por la jurisprudencia. Pero otro tanto se podría decir de las definiciones formuladas por el legislador. Me permito remitir a Núñez Vaquero, A., "Regulación de la interpretación", en Eunomía, vol. 11, 2016, pp 163-175, y a id. "Conceptos dogmáticos: una visión iusrealista", Revus, 30, 2017.

${ }^{56}$ Guastini, R., “Interpretación y construcción jurídica”, en Isonomía, 43, 2015, pp. 11-48. 
Pues bien, no solo es perfectamente posible generar normas en materia probatoria de este modo, sino que sucede con bastante frecuencia: desde la admisión de la prueba por indicios en España, a la concreción de las normas sobre la valoración de la prueba en casi cualquier ordenamiento, pasando por la formulación y especificación de estándares de prueba en sede judicial en Estados Unidos.

Es además importante señalar que las normas que pueden ser objeto de precedente en materia probatoria pueden ser de muy diferente índole, tanto jurídicas como no jurídicas. Bien entendido: cualquier norma puede ser jurídica en el sentido de ser parte de un ordenamiento normativo. No obstante, es frecuente entre los teóricos de la prueba distinguir entre normas probatorias de carácter epistémico y normas probatorias jurídicas, estando las primeras destinadas a la averiguación de la verdad, mientras que las segundas protegerían algún otro valor o principio jurídico. Sin embargo, tanto unas normas como las otras pueden convertirse en precedentes, siendo el criterio para considerarlas como precedentes únicamente que hayan sido empleadas o formuladas en contextos jurisdiccionales, y que se les atribuya algún grado de vinculatoriedad.

\section{UNA ÚlTima (Y SANA) ADVERTENCIA ESCÉPTICA}

Considero inoportuno finalizar este trabajo sin llamar la atención sobre la necesidad de un sano escepticismo en materia de precedentes sobre hechos, pero también de cualquier otro tipo de precedentes. Ello porque en no pocas ocasiones se ha confiado excesivamente en los precedentes como instrumento para garantizar la seguridad jurídica. En este sentido, se afirma con gran frecuencia que los precedentes vienen a aumentar la seguridad jurídica precisamente porque las decisiones de los jueces se ven sometidas a reglas.

Ahora bien, antes que eliminar la inseguridad jurídica o aumentar la determinación del ordenamiento, lo que hacen los precedentes es modificar tal indeterminación y la respectiva incertidumbre. Solo dependiendo de cómo estén formulados los precedentes y de las prácticas interpretativas de la comunidad, la inseguridad podrá reducirse (aunque nada impide que aumente). La razón es que los precedentes -en sentido estricto, las rationes decidendi-son normas, y aquellas están formuladas mediante enunciados a los que es preciso dotar de significado. El problema es precisamente que al afrontar la interpretación de los precedentes nos encontramos con los mismos problemas que enfrentamos a la hora de atribuir significado a los enunciados normativos: equivocidad y vaguedad.

No es este el lugar indicado para dar cuenta de los problemas interpretativos que enfrentamos a la hora de dotar de significado a los precedentes ${ }^{57}$. Lo que sí es posible decir es que cuando se dota de valor normativo a normas formuladas o empleadas en procesos previos, ya no enfrentaremos un problema de indeterminación de los textos

${ }^{57}$ He tratado de presentar los principales problemas relativos a la determinación de la ratio decidendi en Núñez Vaquero, A., "Sin precedentes: una mirada escéptica a la regla del stare decisis”, ob. cit. 
procedentes de autoridades legislativas, sino un problema acerca de cómo debemos interpretar la decisión judicial que da origen al precedente. A ello hay que añadir que con gran frecuencia, especialmente en los ordenamientos del civil law, la regla del stare decisis es una norma implícita, por lo que resulta especialmente complicado desentrañar qué grado de vinculación tiene o cuándo una decisión jurisdiccional cuenta como precedente.

\section{A MODO DE CONCLUSIÓN}

En el presente trabajo hemos partido analizando qué se iba a entender por precedente, stare decisis y ratio decidendi (y obiter dicta). Ello nos ha permitido acotar el campo de investigación en relación con los precedentes: aquello que puede ser precedente son decisiones jurisdiccionales que contienen al menos una norma -empleada o formulada en la justificación interna o externa de una decisión jurisdiccional, pero no la norma individual del caso- a la que se le atribuye algún valor normativo para casos diferentes a aquel en el que fue empleada (o mencionada).

En segundo lugar, hemos descartado una aproximación a los precedentes mediante la teoría de las fuentes del derecho. Ello debido a que la noción de fuentes es tremendamente ambigua y este tipo de aproximación suele resolverse en un expediente de carácter fuertemente formalista.

En su sustitución, aquí se ha adoptado una aproximación más empirista acerca de cuándo existe un sistema de precedentes en un ordenamiento judicial ${ }^{58}$. En tal sentido, si bien existe un sistema con menor grado de vinculatoriedad de los precedentes, se ha optado por identificar la existencia de un sistema de precedentes vinculantes con el hecho de que los operadores jurídicos consideren la presencia de un precedente como una razón relevante a la hora de tomar una decisión. Y dicha relevancia ha sido a su vez definida -recurriendo a la noción de relevancia normativa 2 de Alchourrón y Bulygincomo la consideración más justificada de aquella decisión que, frente a otras decisiones prima facie igualmente justificadas, cuenta en su favor con un precedente.

En tercer lugar, hemos intentado disolver la ambigüedad de la que padece la expresión "hechos probados", mostrando que puede referirse tanto a hechos que han sido objeto de actividad probatoria considerados verdaderos, así como a enunciados que gozan de un especial reconocimiento por parte del derecho. Tal reconocimiento consiste en que aquellos son condición de validez de la decisión jurisdiccional. Dicho con más precisión: condición de la aplicabilidad de la norma individual producto de la decisión jurisdiccional en la que se aplica el precedente. Será condición necesaria, suficiente o meramente contribuyente dependiendo de lo dispuesto por cada ordenamiento.

${ }^{58}$ Esta tesis es más empirista porque no pretende dar cuenta de las creencias de los operadores acerca de qué es lo que ellos creen que hacen, sino que centra su atención -en la tradición del realismo jurídico-en lo que realmente hacen. De este modo, habrá sistema de precedente cuando de hecho los órganos jurisdiccionales empleen esas decisiones pasadas para justificar decisiones posteriores, considerándolos normativamente relevantes al menos en el sentido que hemos visto (relevancia 2 de $A \& B$ ). 
Ese reconocimiento no significa que el enunciado en cuestión sea verdadero, sino solo que aquel es un enunciado sobre hechos reconocido por el derecho. Dicho reconocimiento se plasma en un enunciado que parafrasea el enunciado descriptivo pero que expresa una norma constitutiva individual: aquella precisamente en la que un enunciado sobre hechos individuales forma parte del conjunto de hechos reconocidos por el derecho. Hemos llamado "enunciados calificatorios individuales" a estos enunciados.

No obstante, los enunciados calificatorios individuales no pueden ser precedentes, no por alguna razón conceptual, sino porque los juristas consideran aquello como una extensión de los efectos de la sentencia, aunque sea solo en materia de hechos. Por el contrario, aquellos que pueden ser precedentes son generalizaciones sobre hechos, las que no pueden ser verificadas, aunque sí falseadas. Para ello es suficiente que se otorgue tal reconocimiento institucional al enunciado general.

A continuación hemos distinguido entre precedentes en materia de hechos en sentido estricto y precedentes probatorios. Los primeros son enunciados generales, los que en algunos casos son objeto de procedimiento probatorio indirectamente por medio de la prueba de los enunciados individuales que apoyan -que permiten inferir- el enunciado general; en otros casos, no son en absoluto objeto de ningún procedimiento probatorio, o lo son pero fuera de cualquier procedimiento jurisdiccional.

Dentro de los precedentes en materia probatoria hemos distinguido entre precedentes probatorios interpretativos y precedentes probatorios constructivos. Los primeros fijan como vinculante una interpretación de un enunciado normativo que pretende dirigir la actividad probatoria. Los segundos no son producto de actividad interpretativa sino de construcción jurídica, y tienen como resultado una norma acerca de algún elemento de la prueba. Pueden ser ratio decidendi en este sentido cualquier regla relativa a la actividad probatoria (o a sus resultados).

Hemos finalizado con un aviso acerca de los límites de los precedentes como instrumentos para maximizar la certeza jurídica. Ello porque las rationes decidendi son formuladas mediante enunciados a los que se les debe atribuir significado, es decir, hay que interpretarlos, y dicha tarea afronta los mismos problemas que la interpretación de los enunciados normativos provenientes del legislador.

\section{BIBLIOGRAFÍA}

Alchourrón C. y Bulygin, E., Sistemas normativos, Buenos Aires, Astrea, 2015.

Barberis, M., Europa del diritto, Il Mulino, Bologna 2008.

Barberis, M., "Para una teoría realmente realista del derecho", en Revus, 29, 2016.

Bouvier, H., Gaido, p. y Sánchez Brígido R., "Estudio preliminar. Teoría del derecho y análisis conceptual”, en Raz, J., Alexy, R. y Bulygin, E., Una discusión sobre teoría del derecho, Marcial Pons, Madrid, 2007.

Bustamante, Th., Teoría del precedente judicial, Legales Ediciones, Lima, 2016.

Caracciolo, R., "Existencia de normas", en Isonomía, 7, 1997.

Chiassoni, P., "Los precedentes civiles son vinculantes", en Desencantos para abogados realistas, Bogotá, Universidad del Externado, 2012. 
Cross, R. y Harris, J., El precedente en el Derecho inglés, Marcial Pons, Madrid, 2012.

DeI Vecchi, D., “Acerca de la fuerza de los enunciados probatorios: el salto constitutivo", en Doxa, vol. 37, 2014.

Duxbury, N., The Nature and Authority of Precedent, Cambridge University Press, 2008.

FERNÁNDEZ López, M. "La valoración de pruebas personales y el estándar de la duda razonable", en Cuadernos electrónicos de Filosofía del Derecho, 15, 2007.

Frank, J., Derecho e incertidumbre, Fontamara, México, 2012.

GonzÁlez Lagier, D., "Hechos y conceptos", en Cuadernos electrónicos de filosofía del derecho, Vol. 15, 2007.

GonzÁlez Lagier, D., Quaestio Facti, México, Fontamara, 2013.

GuASTINI, R., "Interpretación y construcción jurídica”, en Isonomía, 43, 2015.

GUASTINI, R., Interpretar y argumentar, CEPC, Madrid, 2014.

Guastini, R., La sintaxis del derecho, Marcial Pons, Madrid, 2016.

Hart, H.L.A., El concepto de derecho, Abeledo-Perrot, México, 2004.

Hospers, J., Introducción al análisis filosófico, Alianza, Madrid, 1982.

Larsen, A. O., "Factual Precedents", en University of Pennsylvania Law Review, 162, 59, 2013.

Llewellyn, K., "Some realism about realism. Responding to Dean Pound", Harvard Law Review, núm. 44, 1931.

Lupo, N. (ed.), Il "precedente" parlamentare tra diritto e politica, Il Mulino, Bologna, 2013.

Magaloni, A. N., El precedente constitucional en el sistema jurídico norteamericano, McGraw-Hill, Madrid, 2001.

Moreso, J. J., y Vilajosana, J. M., Introducción a la teoría del derecho, Marcial Pons, Madrid, 2004.

NúÑez Vaquero, A., "Conceptos dogmáticos: una visión iusrealista”, Revus, 30, 2017.

NúÑEz Vaquero, A., "Regulación de la interpretación”, en Eunomía, vol. 11, 2016.

NúÑEZ Vaquero, A., "Sin precedentes: una mirada escéptica a la regla del stare decisis", en Doxa, vol. 39, 2016.

Romero Seguel, A. "La sentencia judicial como medio de prueba", en Revista Chilena de Derecho, 39, 2, 2012.

Schauer, F., Pensar como un abogado, Marcial Pons, Madrid, 2013.

TRento, S. "El problema de la formación de precedentes en materia probatoria por tribunales supremos. El imperativo que las decisiones judiciales relativas a la prueba de los hechos sean universalizables”, en Ferrer, J. y Vázquez, C. (eds.), Debatiendo con Taruffo, Marcial Pons, Madrid, 2016. 